\title{
Binding of Mutagens to Exopolysaccharide Produced by Lactobacillus plantarum Mutant Strain 301102S
}

\author{
H. Tsuda, ${ }^{*}$ K. Hara, $†$ and T. Miyamoto*1 \\ *Graduate School of Natural Science and Technology, Okayama University, 1-1-1 Tsushima-naka, Okayama 700-8530, Japan \\ †Shikoku Nyugyou Co. Ltd., 955-1 Minamikata, Touon 791-0397, Japan
}

\begin{abstract}
Exopolysaccharide (EPS) was produced by Lactobacillus plantarum 301102 on exposure to the mutagenic action of acridine orange and novobiocin. The biological characteristics of this mutant strain 301102S were the same as those of the parent strain, but fermented milk prepared with the mutant strain showed antimutagenic activity on 3-amino-1,4-dimethyl-5H-pyrido indole. Only EPS-bound cells of strain $301102 \mathrm{~S}$ showed binding ability to mutagens such as heterocyclic amines, and the mutagens were inactivated by binding to EPS. The binding ability was affected by $\mathrm{pH}$; the greatest percentage binding was noted at $\mathrm{pH}$ 8.0. Addition of $\mathrm{Mg}^{2+}$ and sodium dodecyl sulfate, but not oxgall, inhibited the binding ability. Therefore, the binding mechanism of the EPS may consist of ion-exchange and hydrophobic bonds, and the EPS would bind mutagens in the intestine.
\end{abstract}

Key words: exopolysaccharide, Lactobacillus plantarum, probiotic, antimutagenic activity

\section{INTRODUCTION}

Lactic acid bacteria (LAB) are used in many fermented foods particularly fermented dairy products such as cheese, buttermilk, and fermented milk. The $\mathrm{LAB}$ produce lactic acid and diacetyl/acetoin that contribute to the flavor, texture, and shelf life of fermented foods. Fuller (1989) was the first to propose the term "probiotic," and recently, its definition was further refined to "living microorganisms, which upon ingestion in certain numbers, exert health benefits by improving intestinal microbial balance." Probiotic foods belong to the functional food sector and probiotic LAB are a representative of live food ingredients that exert a beneficial effect on the host's health. Fermented dairy products contain much live LAB. Probiotic effects other than

Received July 23, 2007.

Accepted April 27, 2008.

${ }^{1}$ Corresponding author: tmnono@cc.okayama-u.ac.jp restoring intestinal microbial balance are desired and various effects, including immune stimulation, antitumor activity, and cholesterol lowering effect, have been investigated in recent years (Liong and Shah, 2006; Corr et al., 2007).

Lactic acid bacteria starter strains, which play important roles in the processing of fermented dairy products, have been genetically improved to advance or stabilize desirable traits since the 1970s. In the early years, LAB strains were exposed to the mutagenic action of $N$-methyl- $N^{\prime}$-nitro- $N$-nitrosoguanidine (MNNG) or to UV irradiation and desirable mutants were obtained (Kuila et al., 1971; Miyamoto et al., 1983). In the 1980 s, LAB were found to have plasmid DNA sequences that code such significant traits as lactose metabolism, protease production, and citrate metabolism. These useful genes were introduced into LAB by conjugation and transformation with food-grade vectors. However, the construction of vectors for traits that require numerous genetic expressions; for example, exopolysaccharide (EPS) production, is a difficult task.

Exopolysaccharide produced by LAB has received increasing attention mainly because of its function and generally-regarded-as-safe status. Exopolysaccharide plays a major role as natural texturizer in the industrial production of yogurt, cheese, and milk-based desserts. Exopolysaccharides can also function as thickeners, stabilizers, emulsifiers, bodying and gelling agents, or fat replacers in several food products. Important health benefits such as immune stimulation, antimutagenicity, and antitumor activity of fermented dairy products prepared with EPS-producing LAB or EPS itself have been investigated (Kitazawa et al., 1998; Sreekumar and Hosono, 1998b; Chabot et al., 2001).

We have previously reported the isolation of the high bile-resistant and low-pH-resistant autochthonous lactic acid bacterium strain 301102, identified as Lactobacillus plantarum from biological characteristics and 16S rDNA sequence, from traditional home-made cheese in Inner Mongolia, China. This strain showed tolerance in artificial intestinal juice, and the survival rate after $3 \mathrm{~h}$ in artificial gastric juice adjusted to $\mathrm{pH} 2.0$ was $71 \%$, and the minimum inhibitory concentration of 
oxgall was $20 \%$ in De Man, Rogosa, and Sharpe (MRS) broth (Tsuda et al., 2007). The survival and proliferation of orally administered Lactobacillus plantarum 301102 in porcine gastrointestinal tract and increases in the numbers of Lactobacillus and Bifidobacterium in the feces of pigs administered fermented milk prepared with strain 301102 were also reported (Tsuda et al., 2008). In this study, strain 301102 was exposed to the mutagenic action of acridine orange and novobiocin, and genetic variants having the capacity to produce EPS were obtained. The antimutagenic activity against 3-amino-1,4-dimethyl-5 $H$-pyrido indole (Trp-P-1) of fermented milk prepared with the mutant strain, and the binding of amino acid pyrolysates such as Trp-P-1, 2-amino-6-methyldipyrido imidazole (Glu-P-1), 2amino-3,4-dimethyl-imidazo quinoline (MeIQ), and MNNG, were examined. Furthermore, the effects of cation, SDS, and oxgall on the binding ability were investigated.

\section{MATERIALS AND METHODS}

\section{Bacterial Strain}

Lactobacillus plantarum 301102, which was isolated, identified, and stocked in our laboratory, was used. This strain and its mutant were incubated in MRS broth (Oxoid, Basingstoke, UK) and were stocked in 10\% (wt/ vol) reconstituted skim milk (Snow Brand Milk Products, Tokyo, Japan) at $-20^{\circ}$ C. Salmonella typhimurium TA98 was incubated in nutrient broth no. 2 (Oxoid). A $1 \%$ (vol/vol) inoculum was used in all tests.

\section{Mutagenesis}

Strain 301102 was incubated in tryptone-yeast-glucose broth (TYG, $10 \mathrm{~g} / \mathrm{L}$ tryptone, $5.0 \mathrm{~g} / \mathrm{L}$ yeast extract, $5.0 \mathrm{~g} / \mathrm{L}$ glucose, $1.0 \mathrm{~g} / \mathrm{L}$ Tween 80 , and $0.1 \mathrm{~g} / \mathrm{L}$ L-cysteine $\mathrm{HCl}$ monohydrate, $\mathrm{pH} 6.8 \pm 0.2)$ supplemented with acridine orange $(20 \mathrm{mg} / \mathrm{L})$ and novobiocin $(4 \mathrm{mg} / \mathrm{L})$ for $24 \mathrm{~h}$ at $30^{\circ} \mathrm{C}$ and then transferred to the same medium continuously. Each subculture was spread on an MRS agar plate, and using a loop, the colonies were evaluated to determine if they could form thread-like strands after incubation for $48 \mathrm{~h}$ at $30^{\circ} \mathrm{C}$.

\section{Characteristics of the Mutant Strain}

Biochemical tests including those of growth temperature, lactic acid isomer, and carbohydrate fermentation were performed. The Indian ink method was used to visualize bacterial capsules (Aucken et al., 1996). Plasmid DNA analysis of the strains was performed according to the method of Anderson and McKay (1983).

\section{Isolation of Cell-Surface Exopolysaccharide}

Cell-surface EPS was isolated with a method modified from that of Tallon et al. (2003). Cultures were centrifuged at $15,000 \times g$ for $20 \mathrm{~min}$ at $4^{\circ} \mathrm{C}$. The pellet was washed with sterile physiological saline solution, and the viscous pellet was resuspended in $0.05 \mathrm{M}$ EDTA. The mixture was stirred for $2 \mathrm{~h}$ at $8^{\circ} \mathrm{C}$, and cells were removed by centrifugation at $6,000 \times g$ for $30 \mathrm{~min}$ at $4^{\circ} \mathrm{C}$. The EPS was precipitated with 2 volumes of cold ethanol, followed by incubation for $4 \mathrm{~h}$ at $8^{\circ} \mathrm{C}$. After centrifugation at $6,000 \times g$ for $10 \mathrm{~min}$, the pellet containing EPS was dissolved in deionized water. Exopolysaccharide was precipitated with ethanol again, and the EPS that dissolved in deionized water was lyophilized.

The lyophilized EPS was analyzed for carbohydrate and protein content. The total amount of carbohydrate in the lyophilized EPS was determined using the phenol-sulfuric acid method (Dubois et al., 1956) with glucose as standard. Protein content was determined with the Bradford method (Bradford, 1976) using BSA as standard.

\section{Ames Test}

For the Ames test, fermented milk was prepared as follows: $10 \%$ (wt/vol) reconstituted skim milk, inoculated with strain 301102 and the mutant, respectively, was incubated for $72 \mathrm{~h}$ at $30^{\circ} \mathrm{C}$. Salmonella typhimurium TA98 was incubated for $8 \mathrm{~h}$ at $37^{\circ} \mathrm{C}$ with shaking.

A mixture of $100 \mu \mathrm{L}$ of $S$. typhimurium TA98 culture, $100 \mu \mathrm{L}$ of S9 mix (Kikkoman, Tokyo, Japan), $100 \mu \mathrm{L}$ of Trp-P-1 (Wako Pure Chemical, Osaka, Japan) solution $(5 \mu \mathrm{g} / \mathrm{mL}), 100 \mu \mathrm{L}$ of sample (i.e., fermented milk or lyophilized EPS solutions; final concentration: 0.01, 0.1 , and $1.0 \mathrm{mg} / \mathrm{mL}$ ) and $600 \mu \mathrm{L}$ of $0.1 M$ phosphate buffer ( $\mathrm{pH} 7.0$ ) were incubated for $30 \mathrm{~min}$ at $37^{\circ} \mathrm{C}$. After incubation, the mixture was poured onto minimal glucose agar plates $[20 \mathrm{~g} / \mathrm{L}$ glucose, $15 \mathrm{~g} / \mathrm{L}$ agar, $20 \mathrm{~mL} / \mathrm{L}$ of $50 \times$ Vogel-Bonner solution $\left(10 \mathrm{~g}\right.$ of $\mathrm{MgSO}_{4} \cdot 7 \mathrm{H}_{2} \mathrm{O}, 100$ $\mathrm{g}$ of citric acid- $\mathrm{H}_{2} \mathrm{O}, 500 \mathrm{~g}$ of $\mathrm{K}_{2} \mathrm{HPO}_{4}$ anhydrous, and $175 \mathrm{~g}$ of $\mathrm{NaNH}_{4} \mathrm{HPO}_{4} \cdot 4 \mathrm{H}_{2} \mathrm{O}$ in $670 \mathrm{~mL}$ of distilled water)] with $2 \mathrm{~mL}$ of molten top agar $(0.75 \%$, containing $0.05 \mathrm{~m} M$ histidine and $0.05 \mathrm{~m} M$ biotin) and incubated at $37^{\circ} \mathrm{C}$ for $48 \mathrm{~h}$ (Ames et al., 1975). Antimutagenic activity was calculated with the following equation:

Antimutagenic activity $(\%)=[1-(\mathrm{C}-\mathrm{S}) /(\mathrm{C}-\mathrm{B})] \times 100$, where $\mathrm{C}=$ number of mutagen-induced revertants observed in the absence of sample; $\mathrm{S}=$ number of mutagen-induced revertants observed in the presence of sample; and $\mathrm{B}=$ number of spontaneous revertants. 


\section{Preparation of Cells}

The cultures were centrifuged at $15,000 \times g$ for $20 \mathrm{~min}$ at $4^{\circ} \mathrm{C}$. The viscous pellet was obtained after washing in sterile physiological saline solution. Capsular cell (cell and EPS attached to the cell surface) suspension was prepared as follows: the viscous pellet was suspended in an equivalent volume to the culture phosphate buffer (pH 7.0). The cell suspension was prepared as follows: the viscous pellet was suspended in $0.05 M$ EDTA and the mixture was stirred for $2 \mathrm{~h}$ at $8^{\circ} \mathrm{C}$. Then, the supernatant was removed by centrifugation at $6,000 \times g$ for $30 \mathrm{~min}$ at $4^{\circ} \mathrm{C}$. This procedure was performed twice. The obtained nonviscous pellet was washed with phosphate buffer ( $\mathrm{pH}$ 7.0) twice and resuspended in phosphate buffer ( $\mathrm{pH} 7.0$ ) in a volume equivalent to that of the culture. Peptidoglycan was prepared according to Tanabe et al. (1991) and suspended $(1.0 \mathrm{mg} / \mathrm{mL})$ in phosphate buffer ( $\mathrm{pH} 7.0)$.

\section{Binding of Mutagen}

The mutagens Trp-P-1, Glu-P-1 (Wako Pure Chemical), MeIQ (Wako Pure Chemical), and MNNG (Nacalai Tesque, Kyoto, Japan) were used to investigate binding properties. Mixtures of $0.1 \mathrm{~mL}$ of mutagen solution (0.1 $\mathrm{mg} / \mathrm{mL}$ ) and $0.9 \mathrm{~mL}$ of capsular cell, cell, and peptidoglycan suspensions, respectively, were incubated at $37^{\circ} \mathrm{C}$ for $30 \mathrm{~min}$ and filtered (pore size of $0.20 \mu \mathrm{m}$, Minisalt, Sartorius, Gottingen, Germany). Mutagens in the filtrate were quantified with a reverse-phase HPLC system (Shim-Pack CLC-ODS column, Shimadzu, Kyoto, Japan). A mobile phase of $0.1 M$ citrate, $0.2 M$ disodium hydrogen phosphate ( $\mathrm{pH} 3.0$ ), acetonitrile, and triethylamine (60:40:0.05) was used, and the absorbance was measured at $254 \mathrm{~nm}$ (Sreekumar and Hosono, 1998a). Mixtures in which phosphate buffer was substituted for suspensions were run as positive controls. Percentage binding was calculated with the following equation:

$$
\begin{gathered}
\text { Percentage binding }(\%)= \\
{[1-(\text { peak area of Trp-P-1 solution }}
\end{gathered}
$$

with samples/peak area of positive control)] $\times 100$.

Mixtures of $0.9 \mathrm{~mL}$ of capsular cell suspension and $0.1 \mathrm{~mL}$ of Trp-P-1 solution $(0.1 \mathrm{mg} / \mathrm{mL})$ containing $\mathrm{MgCl}_{2}$ (final concentrations of $25,50,100$, and $200 \mathrm{mM}$ ), SDS $(1.25,2.5,5.0,10$, and $20 \mathrm{mM}$ ), or oxgall (Becton Dickinson, Sparks, MD; 0.1, 0.2, and 0.4\% wt/vol) were incubated at $37^{\circ} \mathrm{C}$ for $30 \mathrm{~min}$ and percentage binding was determined as described above. All assays were performed at least 3 times.

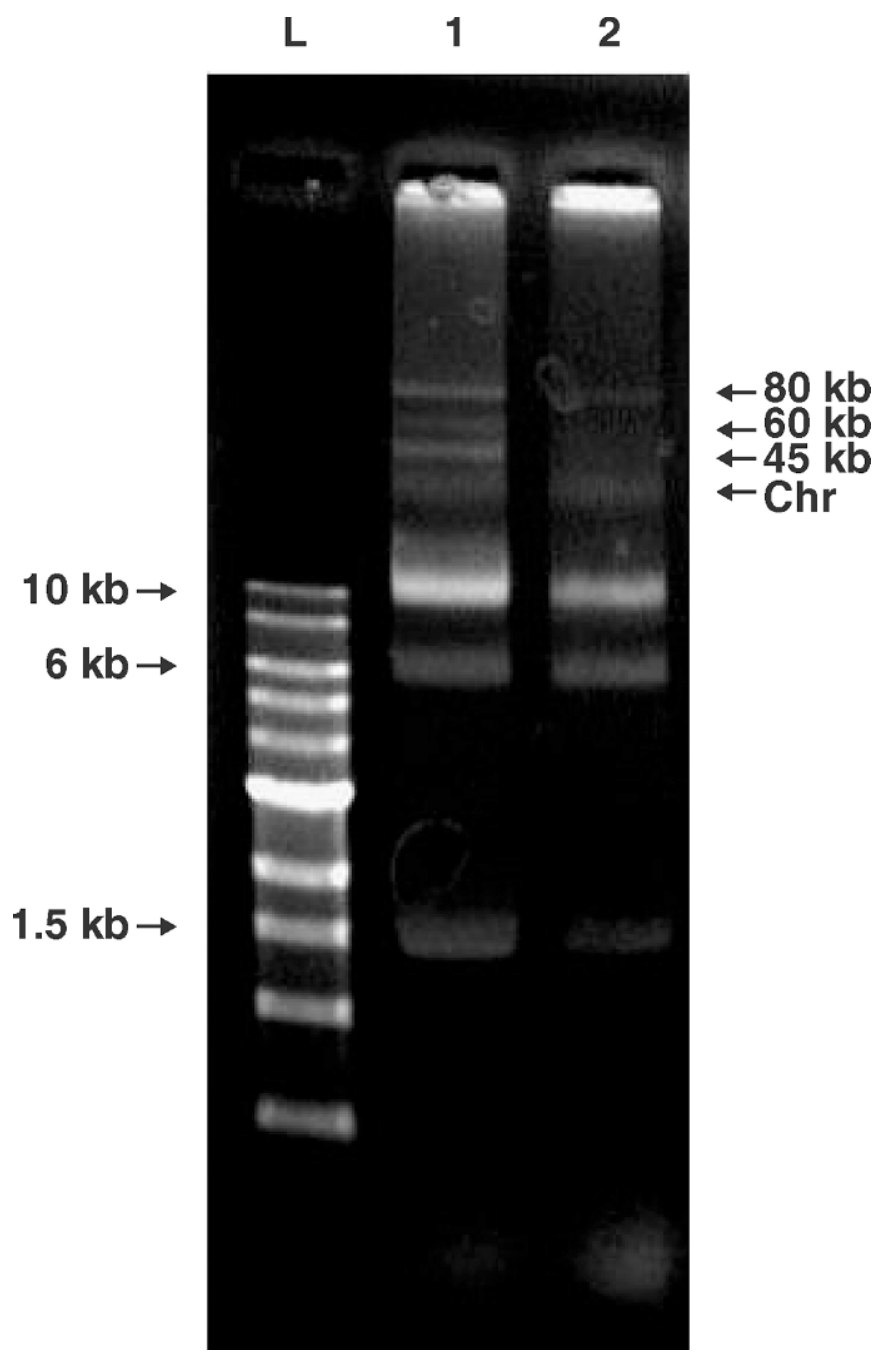

Figure 1. Agarose gel electrophoretic patterns of plasmid DNA sequences isolated from Lactobacillus plantarum strains 301102 and 301102S. Lane $\mathrm{L}=1-\mathrm{kb}$ molecular weight ladder; lane $1=L b$. plantarum 301102; lane $2=L b$. plantarum 301102S; Chr = chromosomal DNA.

\section{RESULTS AND DISCUSSION}

\section{Characteristics of EPS-Producing Mutant Strain}

The parent strain 301102 belonged to the mesophilic and homofermentative lactobacilli group and the lactic acid isomer produced was DL (D:L $=1: 1)$. Acid production from arabinose, rhamnose, and xylose was not observed. Strain 301102 was identified as Lactobacillus plantarum from these results and 16S rDNA sequence. This strain harbored 80-, 60-, 45-, 10-, 6-, and 1.3-kb plasmids (Tsuda et al., 2007).

One mutant whose colony formed thread-like strands with the inoculating loop was isolated after transferring 


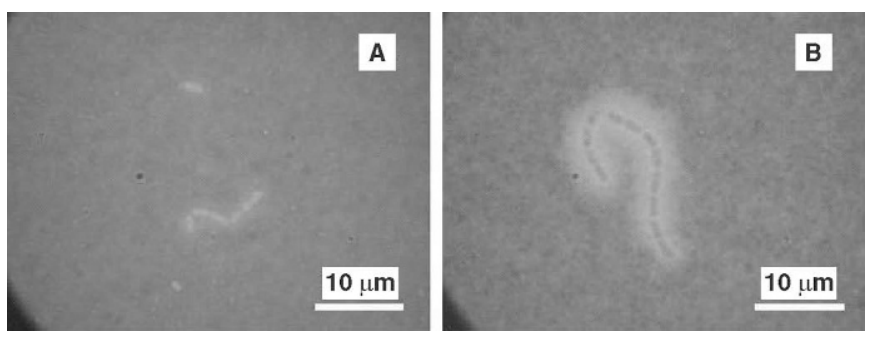

Figure 2. Microscopic observation of encapsulated cells stained with Indian ink. $\mathrm{A}=$ Lactobacillus plantarum $301102 ; \mathrm{B}=$ mutant strain $301102 \mathrm{~S}$

10 times in TYG broth containing acridine orange and novobiocin. Biological characteristics (growth temperature and carbohydrate fermentation) of mutant strain $301102 \mathrm{~S}$ were the same as those of the parent strain, Lb. plantarum 301102. Furthermore, plasmid DNA pattern of mutant strain was same as that of parent strain although the 60 - and $45-\mathrm{kb}$ plasmid DNA were absent (Figure 1). Indian ink staining demonstrated that the viscous substance that formed a clear zone was around the cell (Figure 2). That the lyophilized capsular substance produced by mutant strain $301102 \mathrm{~S}$ contained $81 \%$ carbohydrate and $3.1 \%$ protein is proof that the viscous substance was EPS. Fermented milk prepared with mutant strain $301102 \mathrm{~S}$ showed antimutagenic activity on Trp-P-1, whereas that prepared with the parent strain did not (Table 1).

The ability to produce EPS is unstable in LAB and may be lost following numerous transfers, prolonged storage, or incubation at temperatures above that optimal for growth (Cerning, 1990). Exopolysaccharide productivity of mutant strain 301102S remained stable after 300 incubations at $37^{\circ} \mathrm{C}$ for $24 \mathrm{~h}$. The EPS productivity of strain $301102 \mathrm{~S}$ could be induced by a mutation in the DNA; however, we did not examine what event converted parent strain 301102 into the EPS-producing mutant.

\section{Binding of Mutagen}

The binding abilities to Trp-P-1 of capsular cells, cells, and peptidoglycan of strains 301102 and 301102S were investigated (Figure 3). Only capsular cells of the mutant strain bound Trp-P-1 (54.7\%). Capsular cells of strain 301102S bound other mutagens such as Glu-P1, MeIQ, and MNNG, although the binding abilities for those mutagens were lower than that for Trp-P-1 (Figure 4). The effects of incubation time (10, 20, 30, and $60 \mathrm{~min}), \mathrm{pH}(4.0,5.0,6.0,7.0$, and 8.0), cation, SDS, and oxgall on binding ability were investigated. Mutagen binding occurred within $10 \mathrm{~min}$ and prolongation of incubation time (up to $60 \mathrm{~min}$ ) had no influence
Table 1. Antimutagenic activities (mean value $\pm \mathrm{SD}, \mathrm{n}=3$ ) against 3-amino-1,4-dimethyl-5H-pyrido indole (Trp-P-1) of fermented milk prepared with strains 301102 and 301102S and lyophilized exopolysaccharide (EPS)

\begin{tabular}{lc}
\hline Sample & $\begin{array}{c}\text { Antimutagenic } \\
\text { activity }(\%)\end{array}$ \\
\hline Fermented milk with 301102 & $\mathrm{ND}^{1}$ \\
Fermented milk with $301102 \mathrm{~S}$ & $45.8 \pm 4.6$ \\
Lyophilized EPS & \\
$0.01 \mathrm{mg} / \mathrm{mL}$ & $9.1 \pm 8.2$ \\
$0.1 \mathrm{mg} / \mathrm{mL}$ & $48.3 \pm 0.5$ \\
$1.0 \mathrm{mg} / \mathrm{mL}$ & $82.7 \pm 4.0$ \\
\hline
\end{tabular}

${ }^{1}$ Not detected.

on the binding (Figure 5). The binding ability was strongly affected by $\mathrm{pH}$ of phosphate buffer, $\mathrm{MgCl}_{2}$, and SDS (Figures 6 and 7). The greatest percentage binding was noted at $\mathrm{pH}$ 8.0. Addition of $\mathrm{MgCl}_{2}$ at the final concentration of $50 \mathrm{mM}$ inhibited the binding ability and decreased percentage binding to $20 \%$. Addition of SDS at $10 \mathrm{~m} M$ inhibited the binding ability almost completely. In contrast, binding ability was not affected by the addition of oxgall up to $0.4 \%$ (Figure 7 ).

Many studies have shown that LAB cells and peptidoglycan could bind foodborne mutagens such as heterocyclic amines (Tanabe et al., 1991; Zhang and Ohta,

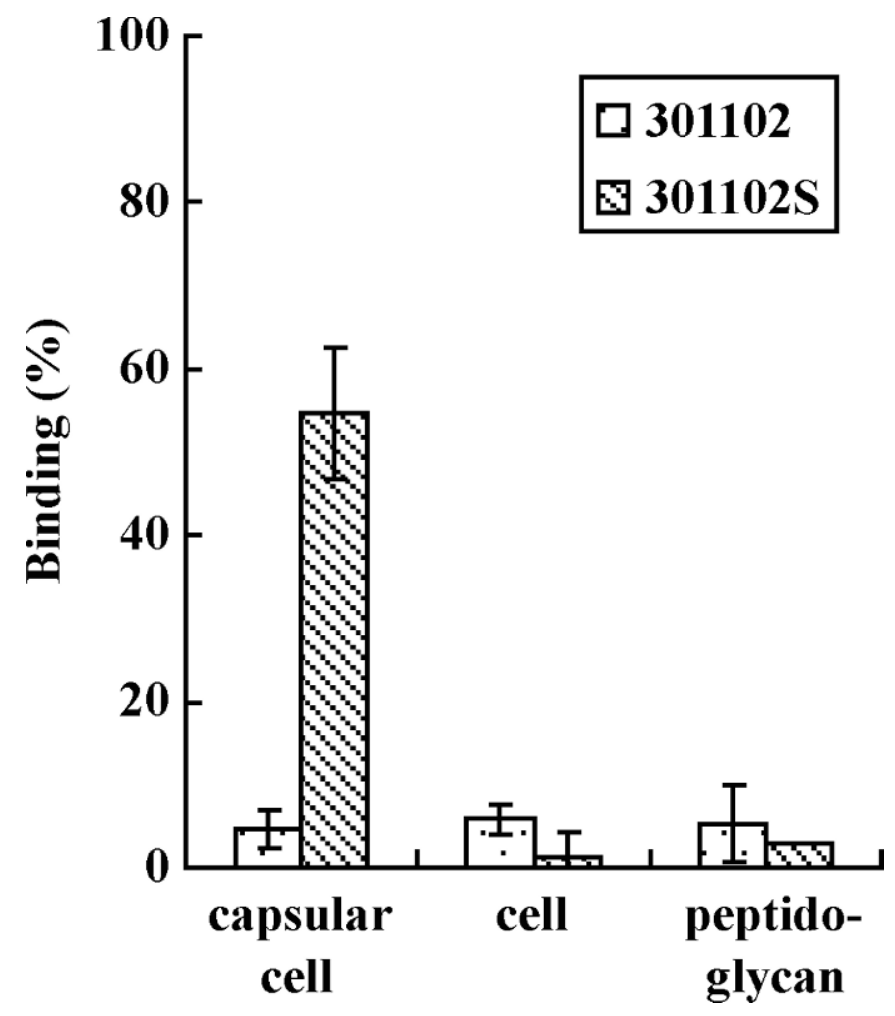

Figure 3. Binding ability against 3 -amino-1,4-dimethyl-5H-pyrido indole (Trp-P-1) of strains 301102 and 301102S. 


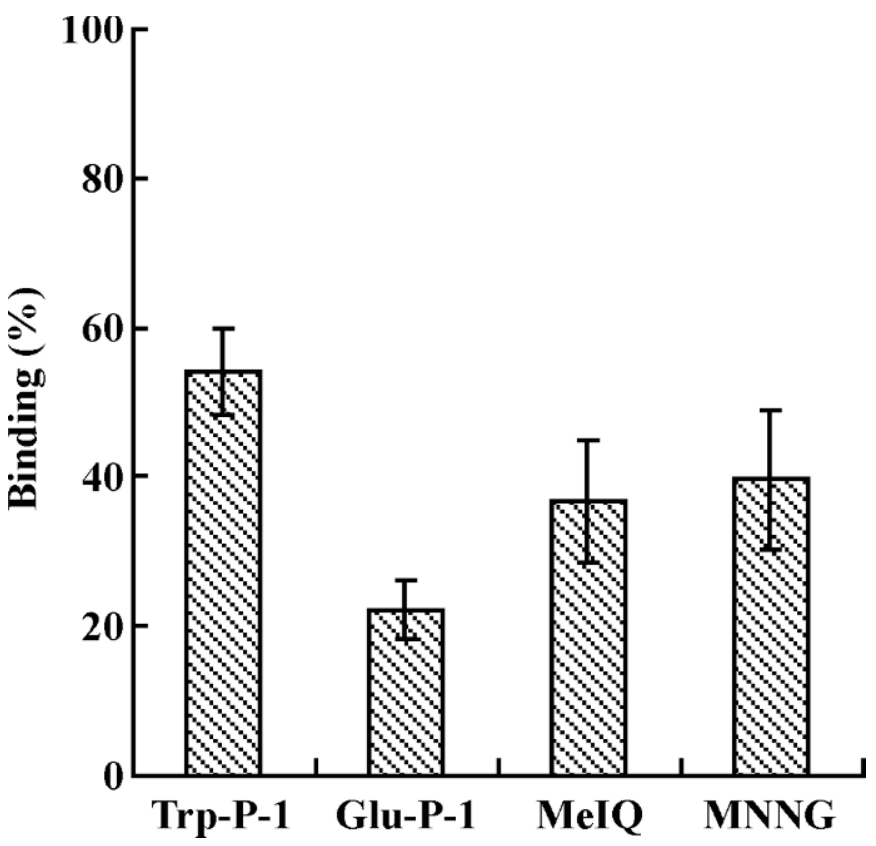

Figure 4. Binding of mutagens 3-amino-1,4-dimethyl-5H-pyrido indole (Trp-P-1), 2-amino-6-methyldipyrido imidazole (Glu-P-1), 2 amino-3,4-dimethyl-imidazo quinoline (MeIQ), and $N$-methyl- $N^{\prime}$-nitro- $N$-nitrosoguanidine (MNNG) to capsular cells of strain 301102S.

1991; Lo et al., 2004). Cells and peptidoglycan of strains 301102 and 301102S showed no binding ability, whereas capsular cells of the mutant strain showed binding ability. This result revealed that the binding ability was due not to cell wall structure but to EPS. Binding modes such as cation exchange and hydropho-

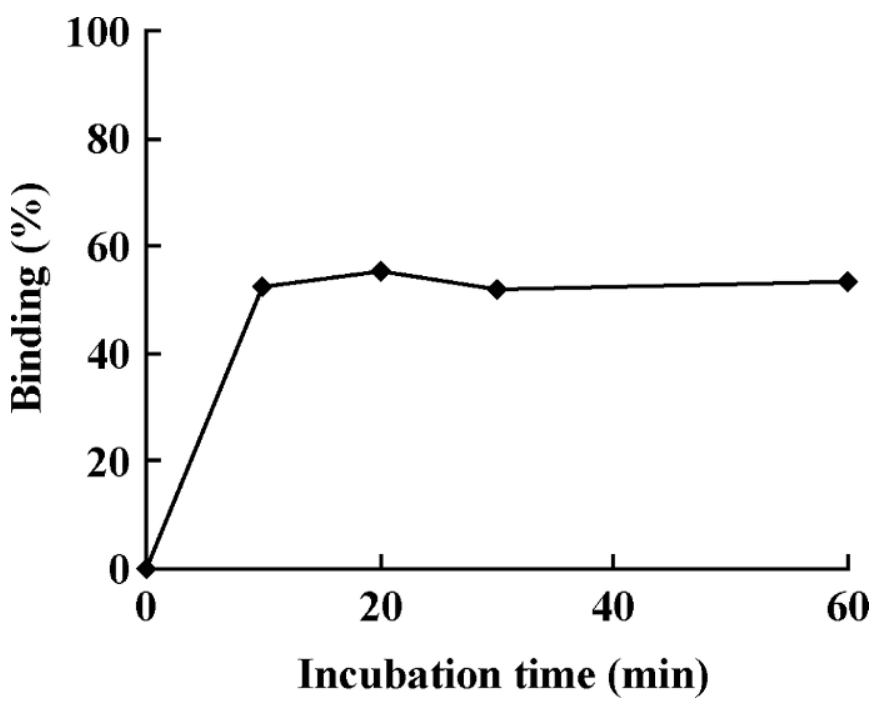

Figure 5. Effect of incubation time on the binding of 3-amino1,4-dimethyl-5H-pyrido indole (Trp-P-1) to capsular cells of strain 301102S; incubation $\mathrm{pH}$ was 7.0.

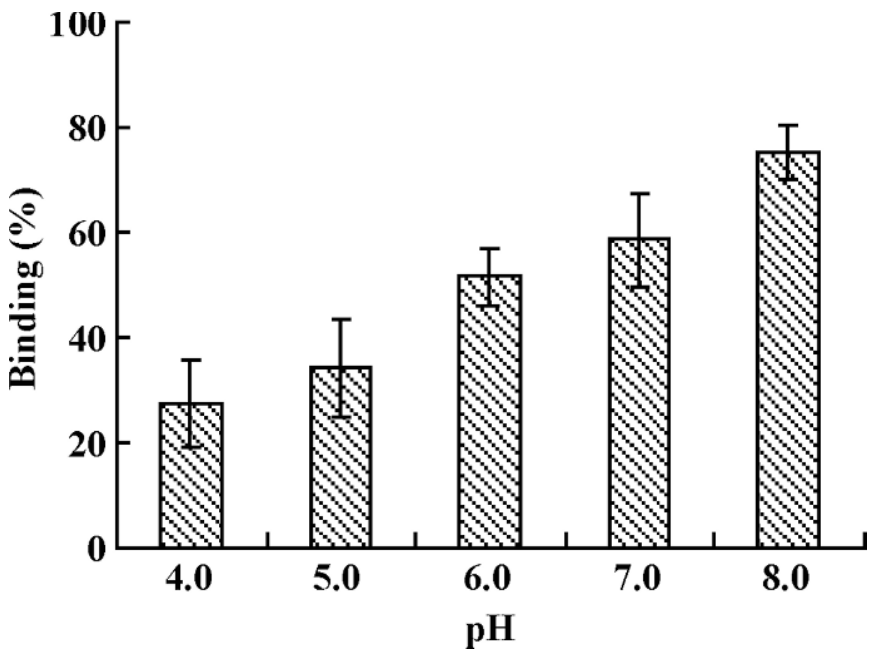

Figure 6. Effect of $\mathrm{pH}$ on the binding of 3-amino-1,4-dimethyl$5 H$-pyrido indole (Trp-P-1) to capsular cells of strain 301102S.

bic bonds of cell walls have been reported, and the binding modes were different among LAB because peptidoglycans show species-specific differences in chemical and structural properties (Morotomi and Mutai, 1986; Tanabe et al., 1991, 1994b). The antimutagenic activities of polysaccharides produced by Bifidobacterium longum and Brevibacterium linens have been reported (Sreekumar and Hosono, 1998b; Hosono et al., 1989), but information on the binding properties of EPS produced by $\mathrm{LAB}$ is limited and little is known about its binding mechanism. In this context, percentage binding was greater for Trp-P-1 (54.2\%) than for Glu-P-1, MeIQ, and MNNG (22.2, 36.6, and $39.7 \%$, respectively), and the greatest binding ability to Trp-P-1 was shown at $\mathrm{pH}$ 8.0. From these results and considering the $\mathrm{pKa}$ values of Trp-P-1, Glu-P-1, MeIQ, and MNNG (10.88, 6.33, 6.54 , and 3.82 , respectively), the ion-exchange mechanism was proposed to be involved in the binding mode. In fact, the addition of $\mathrm{Mg}^{2+}$ inhibited the binding ability to Trp-P-1 by $66 \%$. Moreover, the addition of SDS inhibited the ability almost completely, and high percentage binding to MNNG was noted compared with binding to Glu-P-1 and MeIQ. This is explained by the fact that the binding mode may consist of not only cation exchange but also hydrophobic bond structures. It has been reported that the addition of cations inhibited binding of mutagen to cell walls, and binding to cell walls was inhibited almost completely in the presence of SDS (Hosono et al., 1988; Tanabe et al., 1991, 1994b). The results of this study using EPS agreed with these inhibitory actions of cell walls and the binding ability of cell wall might be due to the carbohydrate moieties in bacterial cells. 

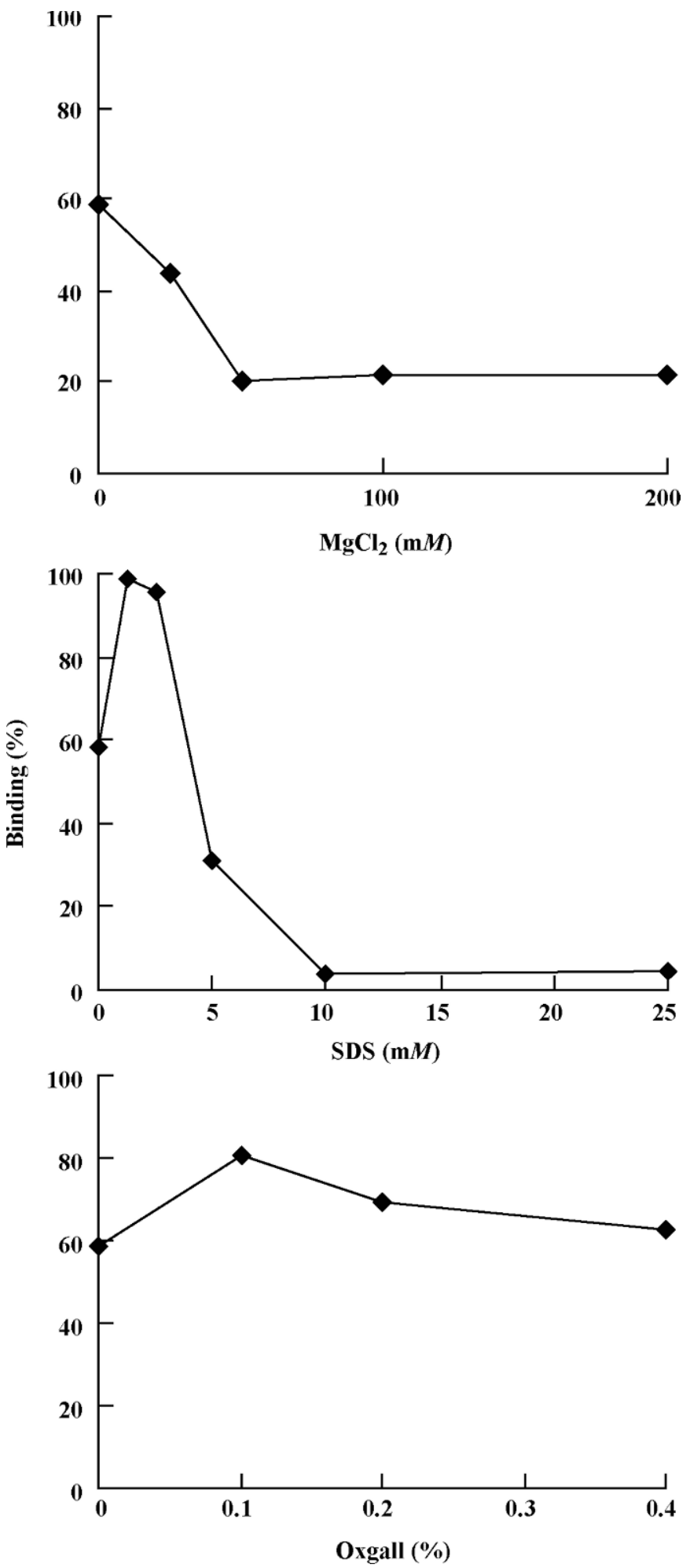

Figure 7. Effect of $\mathrm{MgCl}_{2}$, SDS, and oxgall on the binding of 3 amino-1,4-dimethyl-5H-pyrido indole (Trp-P-1) to capsular cells of strain $301102 \mathrm{~S}$; incubation $\mathrm{pH}$ and time were 7.0 and $30 \mathrm{~min}$.
Bile acid strongly inhibited the binding of amino acid pyrolysates to LAB cells (Tanabe et al., 1994a; Lo et al., 2004). Bile acid is synthesized in hepatocytes from cholesterol and excreted to the intestine where the $\mathrm{pH}$ is approximately 6 to 8 . The solution of oxgall (10\%) corresponds to raw bile (i.e., a $3 \%$ bile concentration corresponds to $0.3 \%$ oxgall concentration). Bile concentration ranged from 1.5 to $2.0 \%$ in the first hour of digestion. Bile acid is toxic to living cells because it has the ability to disrupt the ordered structure of biological membranes. In this study, oxgall addition up to $0.4 \%$ did not inhibit the binding ability of EPS. This is because the EPS structure was stable in bile, in contrast to cell wall structures that were destroyed by bile acid, thereby affecting mutagen binding sites on the cell walls. Although we have no information about the binding of mutagens to EPS produced by 301102S in the digestive tract, the present study reinforces the idea that EPS could bind mutagens in the intestine.

\section{Antimutagenic Activity of EPS}

Lyophilized EPS showed concentration-dependent antimutagenic activity (Table 1). The binding to EPS reduced the mutagenic action of Trp-P-1, suggesting that the binding property of EPS resulted in antimutagenic activity of fermented milk prepared with strain 301102S.

\section{CONCLUSIONS}

In this study, Lb. plantarum 301102 was exposed to the mutagenic action of acridine orange and novobiocin and the EPS-producing mutant strain 301102S was obtained. The EPS productivity of this strain was stable even after 300 incubations for $24 \mathrm{~h}$ at $37^{\circ} \mathrm{C}$. This EPS showed mutagen binding ability and antimutagenic activity. The binding ability of the EPS was influenced by $\mathrm{pH}$, cation, and SDS. Thus, the binding mechanism may consist of ionic bond and hydrophobic bond. Further work is needed to estimate a probiotic property of Lb. plantarum $301102 \mathrm{~S}$ and whether the EPS produced by this strain could bind foodborne mutagens in vivo. Additional work is contemplated to examine the enzymatic and genetic differences between parent and mutant strains to clarify the genetic factors that trigger this mutation.

\section{REFERENCES}

Ames, B. N., J. McCann, and E. Yamasaki. 1975. Methods for detecting carcinogens and mutagens with the Salmonella mammalian-microsome mutagenicity test. Mutat. Res. 31:347-364.

Anderson, D. G., and L. L. McKay. 1983. Simple and rapid method for isolating large plasmid DNA from lactic streptococci. Appl. Environ. Microbiol. 46:549-552. 
Aucken, H. M., S. G. Wilkinson, and T. L. Pitt. 1996. Identification of capsular antigens in Serratia marcescens. J. Clin. Microbiol. 35:59-63.

Bradford, M. M. 1976. A rapid and sensitive method for the quantification of microgram quantities of protein utilizing the principle of protein-dye binding. Anal. Biochem. 72:248-254.

Cerning, J. 1990. Exocellular polysaccharides produced by lactic acid bacteria. FEMS Microbiol. Rev. 87:113-130.

Chabot, S., H. L. Yu, L. de Leseleuc, D. Cloutier, M. R. Van Calsteren, D. Roy, M. Lacroix, and D. Oth. 2001. Exopolysaccharides from Lactobacillus rhamnosus RW-9595M stimulate TNF, IL-6 and IL-12 in human and mouse cultured immunocompetent cells, and IFN- $\gamma$ in mouse splenocytes. Lait 81:683-698.

Corr, S. C., C. G. M. Gahan, and C. Hill. 2007. Impact of selected Lactobacillus and Bifidobacterium species on Listeria monocytogenes infection and the mucosal immune response. FEMS Immunol. Med. Microbiol. 50:380-388.

Dubois, M., K. A. Gilles, J. K. Hamilton, P. A. Rebers, and F. Smith. 1956. Colorimetric method for determination of sugars and related substances. Anal. Chem. 28:350-356.

Fuller, R. 1989. Probiotics in man and animals. J. Appl. Bacteriol. 66:365-378.

Hosono, A., H. Yamazaki, and H. Otani. 1989. Antimutagenicity of slimy substance separated from the culture of Brevibacterium linens. Jpn. J. Zootech. Sci. 60:679-685.

Hosono, A., A. Yoshimura, and H. Otani. 1988. Desmutagenic property of cell walls of Streptococcus faecalis on the mutagenicities induced by amino acid pyrolysates. Milchwissenschaft 43:168170.

Kitazawa, H., T. Harata, J. Uemura, T. Saito, T. Kaneko, and T. Itoh. 1998. Phosphate group requirement for mitogenic activation of lymphocytes by an extracellular phosphopolysaccharide from Lactobacillus delbrueckii ssp. bulgaricus. Int. J. Food Microbiol. 40:169-175.

Kuila, R. K., B. Ranganathan, S. M. Dutta, and H. Laxminarayana. 1971. Induction of mutation in Streptococcus diacetylactis by nitrosoguanidine and ultraviolet irradiation. J. Dairy Sci. 54:331-334.

Liong, M. T., and N. P. Shah. 2006. Effects of a Lactobacillus casei synbiotic on serum lipoprotein, intestinal microflora, and organic acids in rats. J. Dairy Sci. 89:1390-1399.
Lo, P. R., R. C. Yu, C. C. Chou, and E. C. Huang. 2004. Determinations of the antimutagenic activities of several probiotic bifidobacteria under acidic and bile conditions against benzo[a]pyrene by a modified Ames test. Int. J. Food Microbiol. 93:249-257.

Miyamoto, T., N. S. Reddy, and T. Nakae. 1983. Induction of mutation in Lactobacillus casei subsp. alactosus by nitrosoguanidine. Agric. Biol. Chem. 47:2755-2759.

Morotomi, M., and M. Mutai. 1986. In vitro binding of potent mutagenic pyrolyzates to intestinal bacteria. J. Natl. Cancer Inst. 77:195-201.

Sreekumar, O., and A. Hosono. 1998a. Antimutagenicity and the influence of physical factors in binding Lactobacillus gasseri and Bifidobacterium longum cells to amino acid pyrolysates. J. Dairy Sci. 81:1508-1516.

Sreekumar, O., and A. Hosono. 1998b. The antimutagenic properties of a polysaccharide produced by Bifidobacterium longum and its cultured milk against some heterocyclic amines. Can. J. Microbiol. 44:1029-1036.

Tallon, R., P. Bressollier, and M. C. Urdaci. 2003. Isolation and characterization of two exopolysaccharides produced by Lactobacillus plantarum EP56. Res. Microbiol. 154:705-712.

Tanabe, T., H. Otani, and A. Hosono. 1991. Binding of mutagens with cell wall peptidoglycan of Leuconostoc mesenteroides subsp. dextranicum T-180. Milchwissenschaft 46:622-625.

Tanabe, T., K. Suyama, and A. Hosono. 1994a. Effect of pepsin, trypsin or bile acid on the binding of tryptophane pyrolysates by Lactococcus lactis subsp. lactis T-80. Milchwissenschaft 49:438-441.

Tanabe, T., K. Suyama, and A. Hosono. 1994b. Effect of sodium dodecylsulphate on the binding of Lactococcus lactis subsp. lactis T80 cells with Trp-P1. J. Dairy Res. 61:311-315.

Tsuda, H., K. Hara, and T. Miyamoto. 2007. High bile- and low pHresistant lactic acid bacteria isolated from traditional fermented dairy products in Inner Mongolia, China. Milk Sci. 55:129-134.

Tsuda, H., K. Hara, and T. Miyamoto. 2008. Survival and colonization of orally administered Lactobacillus plantarum 301102 in porcine gastrointestinal tract. Anim. Sci. 79:274-278.

Zhang, X. B., and Y. Ohta. 1991. Binding of mutagens by fractions of the cell wall skeleton of lactic acid bacteria on mutagens. J. Dairy Sci. 74:1477-1481. 